\title{
Sleep Deprivation and Academic Performance of Nursing Students in a Tertiary Institution in Cross River State, Nigeria
}

\author{
Regina Etita Ella ${ }^{1}$, Felicia Ekwok Lukpata ${ }^{1} \&$ Josephine L-U Bassey ${ }^{2}$ \\ ${ }^{1}$ Department of Nursing Science, Faculty of Allied Medical Sciences, College of Medicine, University of Calabar, \\ Cross River State, Nigeria \\ ${ }^{2}$ University of Calabar Teaching Hospital (UCTH), Cross River State, Nigeria \\ Correspondence: Regina Etita Ella, Department Of Nursing Science, Faculty of Allied Medical Sciences, College \\ of Medicine, University of Calabar, Cross River State, Nigeria. Tel: 234-803-358-2862. E-mail: \\ retila07@yahoo.com, etitaella57@gmail.com
}

Received: August 19, 2019 Accepted: September 7, 2019 Online Published: September 25, 2019

doi:10.5539/gjhs.v11n11p168 URL: https://doi.org/10.5539/gjhs.v11n11p168

\begin{abstract}
This study investigated sleep deprivation and academic performance on nursing students of University of Calabar. A self-structured instrument was administered to a sample of 109 students. Data was analyzed using SPSS version 20.0. Most, 55(50.5. \%) of the respondents start depriving themselves of sleep immediately after resumption.

On school days, most 53 (48.6\%) respondents sleep for 1-3 hours on average; while 40(36.7\%) respondents sleep for 4-6 hours on average. During weekends most, 69(63.3\%) respondents sleep for 4-6 hours on average, however, during examinations, majority $73(67 . \%)$, sleep for $1-3$ hours on average. 64(58.6\%) take different substances to keep awake. More male 69(63.3\%) respondents start depriving themselves of sleep immediately after resumption, as against 50(46\%) female respondents. Male students have an average sleep of 5.02 hours during schools days; 5.07 hours during weekends, and 2.39 hours during examinations, while female students have an average sleep of 5.25 hours during schools days, 5.43 hours during weekends, and 4.77 hours during examinations. Male students

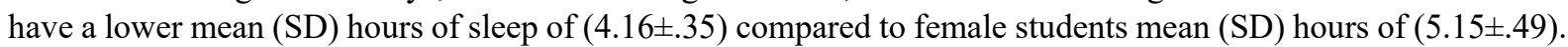
The result further showed a statistically significant relationship between sleep deprivation and academic performance, also, a statistically significant influence of sleep deprivation on academic performance of male and female nursing students. Recommendations: nursing students should be properly counseled on the importance of adequate sleep to their academic performance. They should only deprive themselves of sleep during school days and less during examination.
\end{abstract}

Keywords: academic performance, nursing students, sleep deprivation

\section{Introduction}

Sleep is critical for maintaining a healthy life. Having sufficient of sleep is very essential for an individual's total health (physical, mental, social and cognitive. Although most health organizations recommend 7 to 8 hours of sleep for the average adult, sleep requirements varies per individual. Having quality sleep is one of the important requirements of the learning process for memory and good academic performance for students of various cadres. However many students in tertiary institutions, especially when preparing for examination deprive themselves of sleep through several actions such as smoking, taking bath and or taking of stimulating substances believed to cause insomnia such as coffee, alcoholic beverages, caffeinated drinks, (El Gamdi, 2013; Hershner \& Chervin, 2014).

Sleep deprivation in adults refers to sleep that is shorter than the average basal need of 7 to 8 hours per night (Colten, Attevogt, \& Institute of Medicine, 2007). It refers to sleep that is shorter than the 7 to 8 hours per night as recommended by health organizations (Otenyo, 2015). It could therefore be said that sleep deprivation is a condition of not having enough sleep in relation to an individual's physiological and developmental requirements. One of the main symptoms of sleep deprivation is excessive daytime sleepiness in addition to poor memory, poor concentration, and depressed mood (Colten, Attevogt, \& Institute of Medicine, 2007). Also Kazim and Abrar (2011) reported that not having sufficient sleep can result to emotional instability, memory loss, day time sleepiness and decrease concentration. The phenomenon of sleep deprivation and lack of quality sleep is common 
among college and tertiary education students, especially when their examination is fast approaching. Being unable to get the recommended amount of sleep per night has a negative impact on the next day functioning, and can also be detrimental to health and may lead to poor academic performance.

El Desouky, Lawend and Awed (2015) opined that Nursing students have a rigorous course load, which necessitate hard work and at the same time adequate sleep. They further stated that because of the correlation between sleep, memory formation and learning, sleep is of utmost importance to nursing students, however, when nursing students resume school, their sleep habits and patterns changes. These students typically start practicing a sleep pattern that is characterized by sleep deprivation. Similarly, nursing students in University of Calabar, face very busy daily schedule which most often starts by $7 \mathrm{am}$ and ends by 5 or $6 \mathrm{pm}$. After 8 weeks block (period of concentrated lectures), the students move to the clinical area for concentrated clinical practice which is supposed to last for another 8 weeks before they return to the classroom for semester examinations. But because the first 8 weeks of block is not usually enough for lecturers to complete their lectures, they are usually called back to classroom, daily (sometimes from 2.30 to 5 or $6 \mathrm{pm}$ ) for lectures by different lecturers who may not have completed their course work, and these classes sometimes end with assignments. Given the above situation, some students may decide to either sleep early in the evening in order to wake up later at night to either read or do some assignments, or stay up and sleep late at night for the same purpose. Given the above scenario some students may decide to take actions or substances that can enhance them to stay awake. These actions may affect aspects of the average university student's life including cognition, mood, immune system function, and even lead to substance abuse (Orzech, Salafsky, \& Hamilton, 2011). These actions may have negative impacts on learning, memory and academic performance as well as mental and physiological health.

Cebulko (2010) observed that on average, nursing students reported waking up in the middle of the night or early morning about one to twice a week and used caffeine as a substance to prevent sleep. Otenyo (2015) found out among college students of the University of Arizona in Tucson, Arizona that most students had more sleep during weekends, compared to Monday to school days. The average amount of sleep (4-6 hours) by majority of students was at the begging of the week (Mondays and Wednesdays, compared to 8 or more hours of sleep during weekend - Friday-Sunday. Most of the respondents had an average of 6-8 hours of sleep per night, with most of them not using sleep enhancement substances such as herbal teas, drugs followed by alcohol and caffeinated drinks. A cross-sectional survey by Lund, Reider, Whiting and Prichard (2010), revealed that about sixty percent (60\%) of the respondents had poor-quality sleep, with some taking over the counter and psychoactive drugs to alter sleep pattern. Cates, Clark, Woolley and Saunders (2014) sought to determine the quality of sleep among 253 students comprising 161 females and 92 males.

Many studies have been conducted in respect sleep deprivation and academic performance, with most results pointing to the fact that sleep deprivation affects academic performance of students negatively (Sarbazvatan, Amini, Aminisani, \& Shamshirgaran, 2017; Hershner \& Chervin 2014; Aung \& Nurumal, 2016; Orzech et al., 2011; Desouky, Lawend, \& Awed, 2015). The investigation of Sarbazvatan et al, revealed that sleep quality was a predictor of academic achievement $(\beta=-0.07, P=0.035)$, as lower grades were common among students low sleep quality. Orzech et al. (2011) specifically reported that daytime sleepiness results in decreased attention and concentration, which negatively impacts students' learning and memory, recall ability, whereas Desouky, Lawend and Awed (2015) study among female nursing students at the College of Nursing and Allied Health Sciences in Jazan city, kingdom of Saudi Arabia revealed that students with good total sleep quality have good academic performances. Thomas, McIntosh and Lamar (2016) also opined from the findings of his study that Ninety-eight percent of the student participants believed they would perform better academically of they had more sleep. Cates, Clark, Woolley and Saunders (2014) sought to determine the quality of sleep among 253 students comprising 161 females and 90 males. Results revealed that the rate of poor sleeping was higher among students in the lower GPA category. There was no relationship between gender and overall sleep quality. On the contrary the result of Ghamdi (2013) study on the relationship between sleep deprivation and academic performance of students in collage of nursing at King Saud University, showed that majority of the respondents practiced various habits \{hot drinks $(7.0 \%)$, warm hot bath $(24.6 \%)$, physical exercise 0.9 , watching television $(23.7 \%)$, reading the Quran and hypnotics $(56.1 \%)\}$ to deprive them of sleep especially the night before an examination but did not show any correlation between sleep deprivation and academic achievement. Similarly, the findings of Dotillos, Orong, Payangga, Proel, Simyunn and Torregosa (2011) did not observe any significant relationship between the preferred study time of the respondents and their academic performance

Academic performances of nursing students in University of Calabar have deteriorated in recent years. This is evident in their grades in both internal semester examinations and especially as reflected in the external Registered Nurse (RN) final qualifying Examinations results from Nursing and Midwifery Council of Nigeria from year 2013 
to 2018 highlighted (see Appendix 1). Although, female students are in majority compared to males (in the ratio 608:67), poor academic performances are recorded by both sexes. There is a large gap in research examining the relationship between sleep deprivation and such academic performance (Shochat, Cohen-Zion, \& Tzischinsky, 2014). Ella, Akpabio and Samsom-Akpan (2012) Investigated study habits of undergraduate nursing students in University of Calabar, exclusive of sleep deprivation as a habit. It is therefore the aim of this research to investigate how sleep deprivation affects academic performances of nursing students in University of Calabar.

The purpose of this study was to investigate how sleep deprivation affects academic performances of nursing students in University of Calabar.

The objectives were:

1) To determine the pattern of sleep deprivation among nursing students of university of Calabar.

2) To examine the pattern of sleep deprivation between male and female nursing students' of university of Calabar.

3) To examine the effect of sleep deprivation on nursing students' academic performance of university of Calabar.

4) To examine how sleep deprivation influence male and female nursing students' academic performance of university of Calabar.

\section{Hypotheses}

1) There is no significant relationship between sleep deprivation and academic performance of nursing students of University of Calabar.

2) There is no significant influence of sleep deprivation on academic performance of male and female nursing students of University of Calabar.

\section{Materials and Methods}

Research Design, The descriptive survey was conducted in University of Calabar also known as UNICAL, between August to September 2018, at the Department of Nursing Science, University of Calabar. Study Population The study population comprised of undergraduate students from the Department of Nursing Science, totalling six hundred and fifty-seven (675) undergraduate nursing students. Out of these, 608 are females while males are 67. Also, the 675 students comprise 213 direct entry students and 416 generic students. However, students of third to fifth year students were included in the study. This is because it is only from year 3-5 that medical surgical nursing and oncology diseases are taught. A total of 100 undergraduate nursing students, comprising of 85 females and 15 males was purposely selected for the study. The technique assumes that with good judgment the researcher can include only the sample elements that possess the characteristic of the population. Unwilling students and those not physically present were excluded.

Data was collected using a validated self-structured and pretested questionnaire and students' examination scores on medical/surgical_nursing. The instrument, titled (Nursing Students Sleep Deprivation and Academic Performance Instrument (NSSDACI) was designed to elicit socio-demographic information of the respondents and their pattern of sleep deprivation. The examination scores on the other hand were to elicit information on their academic performances. The instrument yielded a reliability coefficient value of 0.78 which was calculated using spearman's rank order correlation coefficient. Data was collected by the researchers with the help of two trained research assistants. Data were analyzed using SPSS version 20.0 and results were presented using descriptive statistics: mean (X), standard deviation (SD), frequency tables, bar charts, and pie charts and interpreted using percentages, and hypotheses were tested using Pearson's Product Moment Correlation Coefficient and Independent t-test statistics at 0.05 level of significance. Ethical approval was obtained from the Health Research Ethical Committee (HREC) of University. Also self-introduction was made to the dean of the faculty and the head of nursing science department. Informed consent was obtained from all respondents. 


\section{Results}

Table 1. Socio-demographic Data of Respondents $(n=109)$

\begin{tabular}{lcc}
\hline Variables & Frequency & Percentage (\%) \\
\hline Gender: & 27 & 24.8 \\
Male & 82 & 75.2 \\
Female & 48 & \\
\hline Age in years: & 35 & 44.0 \\
$18-22$ & 23 & 32.1 \\
$23-27$ & 3 & 21.1 \\
$28-32$ & & 2.8 \\
$33-37$ & 77 & \\
\hline Marital Status: & 31 & 70.6 \\
Never Married & 1 & 28.4 \\
Married & & 0.9 \\
Divorced & 107 & 98.2 \\
\hline Religion: & 1 & 0.9 \\
Christian & 1 & 0.9 \\
Traditional & & \\
Islam & 51 & 46.8 \\
\hline Year of Study: & 35 & 32.1 \\
Year II & 23 & 21.1 \\
Year III & & \\
Year IV & 26.5 \\
\hline Category of Students: & & \\
Generic & 35.5 \\
Direct Entry & 35 & \\
\hline & & \\
\hline
\end{tabular}

The results in Table 1 revealed that majority, 82 (75.2\%]) of the respondents were females while 27 (24.8\%) respondents were males. Most (48[44.0\%]) of the respondents were between the ages of 18 and 22 years; 35 (32.1\%) respondents were between 23-27 years; 23 (21.1\%) respondents were between 28-32 years; while 3 (2.8\%) respondents were within the age range of 33 and 37 years. In the marital status category, majority (77[(70.64\%]) respondents were never married, $31(28.4 \%)$ respondents were married, while $1(0.9 \%)$ respondents had divorced. Lastly, $51(46.8 \%)$ respondents was a 200 level student, 35 (32.1\%) respondents were 300 level students, while $23(21.1 \%)$ respondents were 400 level nursing students. 
Pattern of sleep deprivation

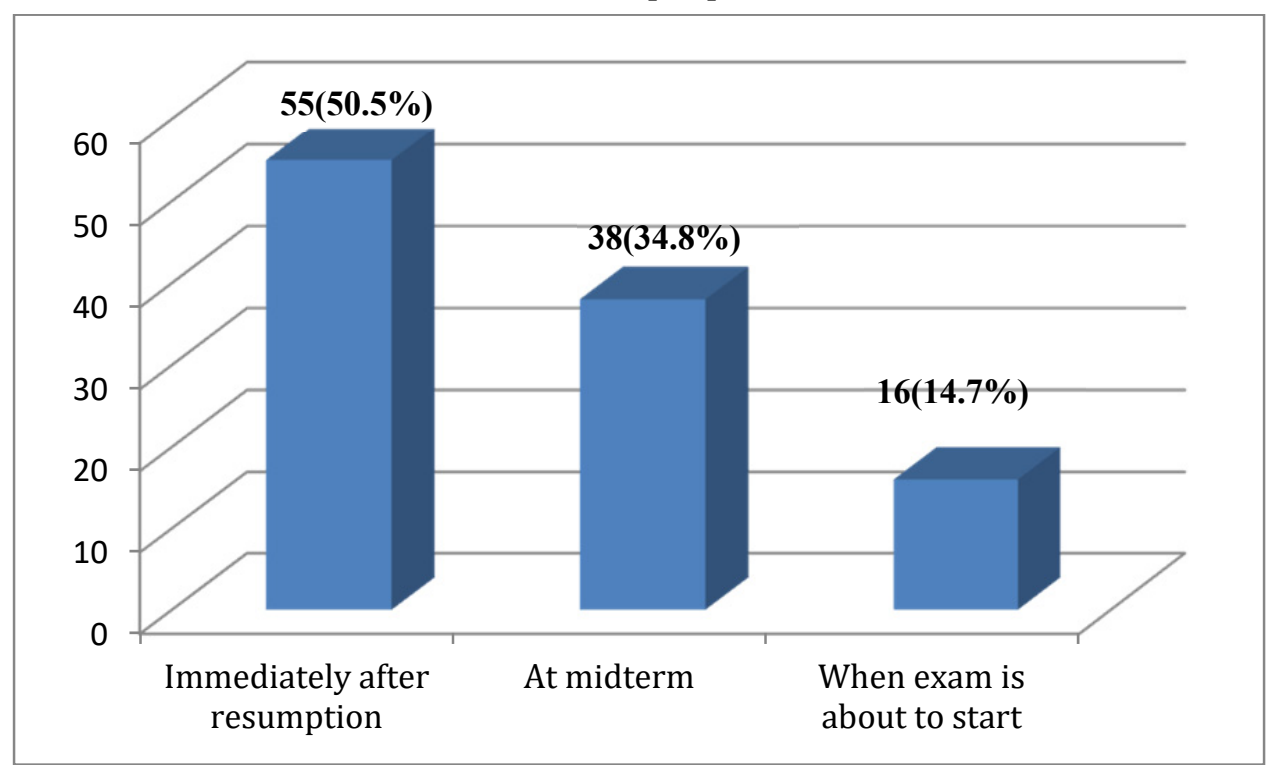

Figure 1. Bar chart showing when students start depriving themselves of sleep to read

Results in Figure 1 showed that $55(50.5 \%)$ respondents start depriving themselves of sleep immediately after resumption, $38(34.8 \%)$ respondents start depriving themselves of sleep at midterm, while $16(14.7 \%)$ respondent starts depriving herself when examination is about to start.

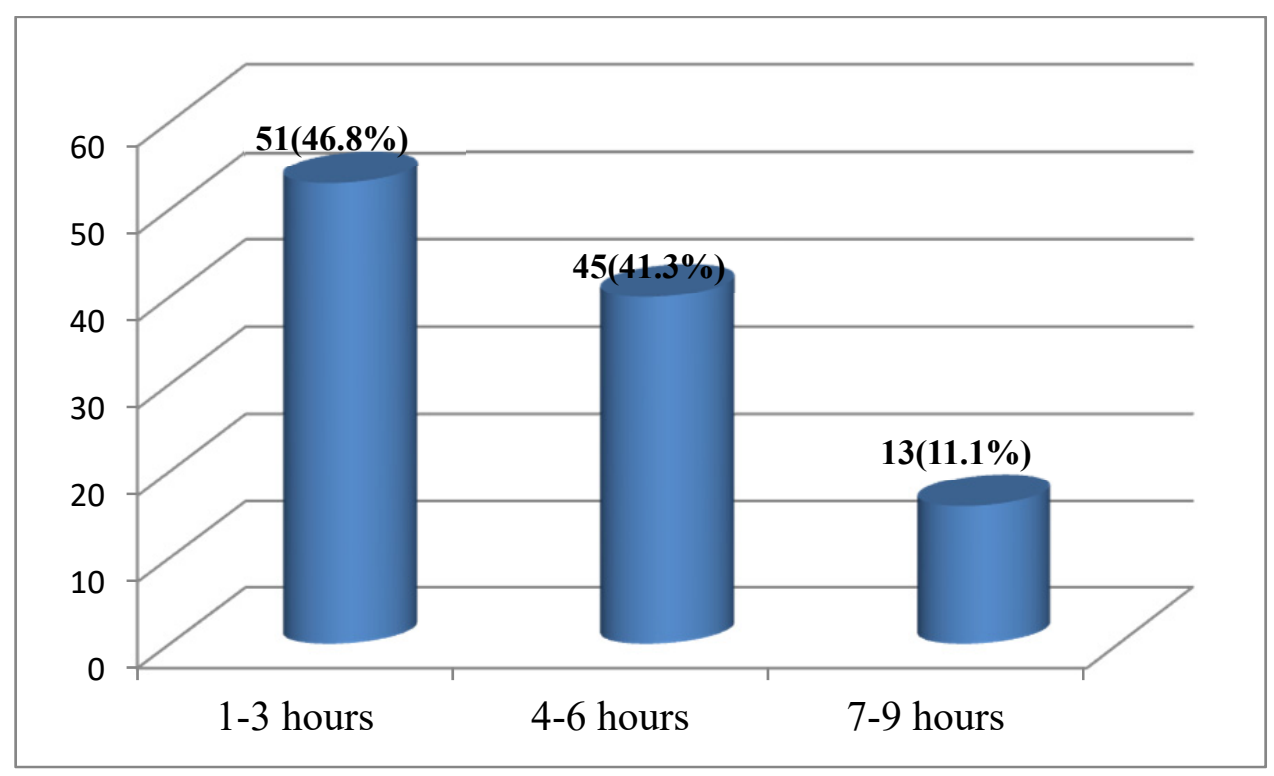

Figure 2. Bar chart showing average hours of sleep by nursing students

Results in Figure 2 showed that $51(46.8 \%)$ respondents sleep for 1-3 hours on average during school days, 45 $(41.3 \%)$ respondents sleep for 4-6 hours on average, while $13(11.9 \%)$ respondent respondents sleep for 7-9 hours on average during school days. 


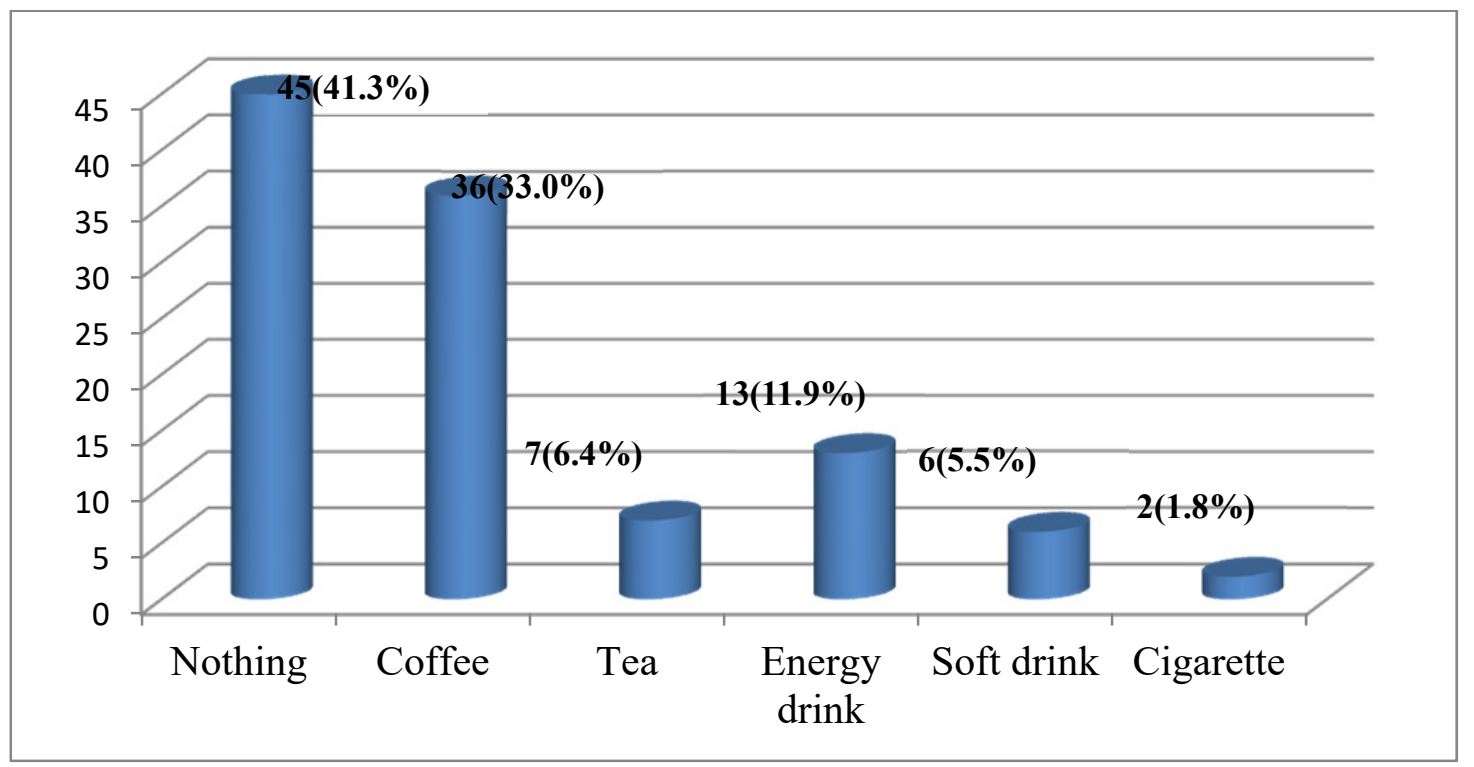

Figure 3. Bar chart showing substances taken by nursing students to keep awake at night

Results in Figure 3 shows that 45 (41.33\%) respondents do not take anything to keep awake at night, 36 (33.0\%) respondents take coffee to keep awake. Seven (6.4\%) of the respondents often take tea. Respondents who take energy drink to keep awake at night are $13(11.9 \%), 6(5.5 \%)$ respondents often take soft drinks, while $2(1.8 \%)$ respondent often smoke cigarette to keep awake at night.

Pattern of sleep deprivation between male and female nursing students

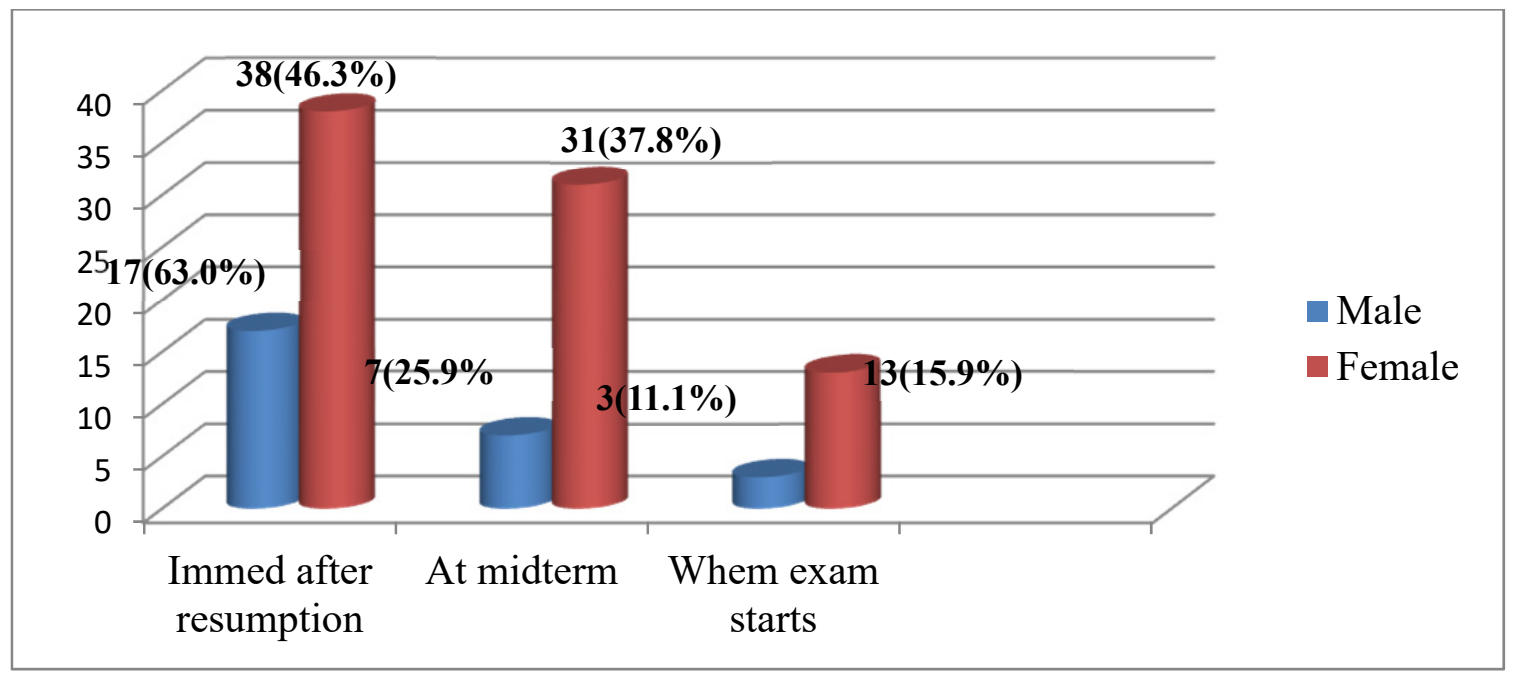

Figure 4. Bar chart comparing when male and female nursing students start depriving themselves of sleep

Results in Figure 4 showed that out of the 27 males that participated in the study 17 (63\%) respondents start depriving themselves of sleep immediately after resumption, 7 (25.9\%) respondents start depriving themselves of sleep at midterm, while $3(11.1 \%)$ respondent starts depriving herself when examination is about to start. Also, out of the 82 females students that participated in the study $38(46.3 \%)$ respondents start depriving themselves of sleep immediately after resumption, $31(37.8 \%)$ respondents start depriving themselves of sleep at midterm, while 13 $(15.9 \%)$ respondent starts depriving herself when examination is about to start.

This result implies that more male respondents start depriving themselves of sleep immediately after resumption, but more female respondents start depriving themselves of sleep during midterm and exam period. 
Table 2. Male and female nursing students' average hours of sleep during school days

\begin{tabular}{|c|c|c|c|c|c|c|c|}
\hline \multirow{2}{*}{ Average hours of sleep during school days } & \multicolumn{3}{|c|}{ Male } & \multicolumn{3}{|c|}{ Female } & \multirow{2}{*}{ Total } \\
\hline & $\mathrm{N}$ & $\bar{X}$ & SD & $\mathrm{N}$ & $\bar{X}$ & SD & \\
\hline 1-3 hours & 18 & 2.56 & .428 & 33 & 2.94 & .242 & 51 \\
\hline 4-6 hours & 7 & 5.00 & .816 & 38 & 5.18 & .766 & 45 \\
\hline 7-9 hours & 2 & 7.50 & .809 & 11 & 7.64 & .707 & 13 \\
\hline Total & 27 & 15.06 & .809 & 82 & 15.76 & 1.715 & 109 \\
\hline Average & & 5.02 & .267 & & 5.25 & .572 & \\
\hline
\end{tabular}

Results in Table 2 revealed that 51 students have an average of 1-3 hours of sleep during schools days, and out of these 18 males have a mean (SD) score of $2.56 \pm .428$, while 33 females have a mean (SD) score of $2.94 \pm .242$. Also, out of 45 students that have an average of 4-6 hour of sleep during school days, 7 males have a mean (SD) score of

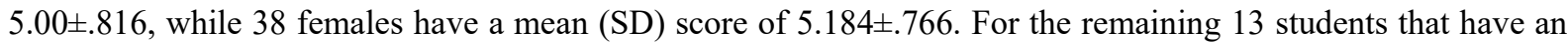
average of 7-9 hour of sleep during school days, 2 males have a mean (SD) score of 7.50土.809, while 11 females have a mean (SD) score of 7.64 \pm .707. Overall, during school days the 27 male students have an average mean (SD) score sleep of 5.02 \pm .267 , while the 82 female have a mean (SD) score of 5.254 \pm .572 . The result shows that male students have slightly less sleep than female students.

Effect of sleep deprivation on nursing students' academic performance

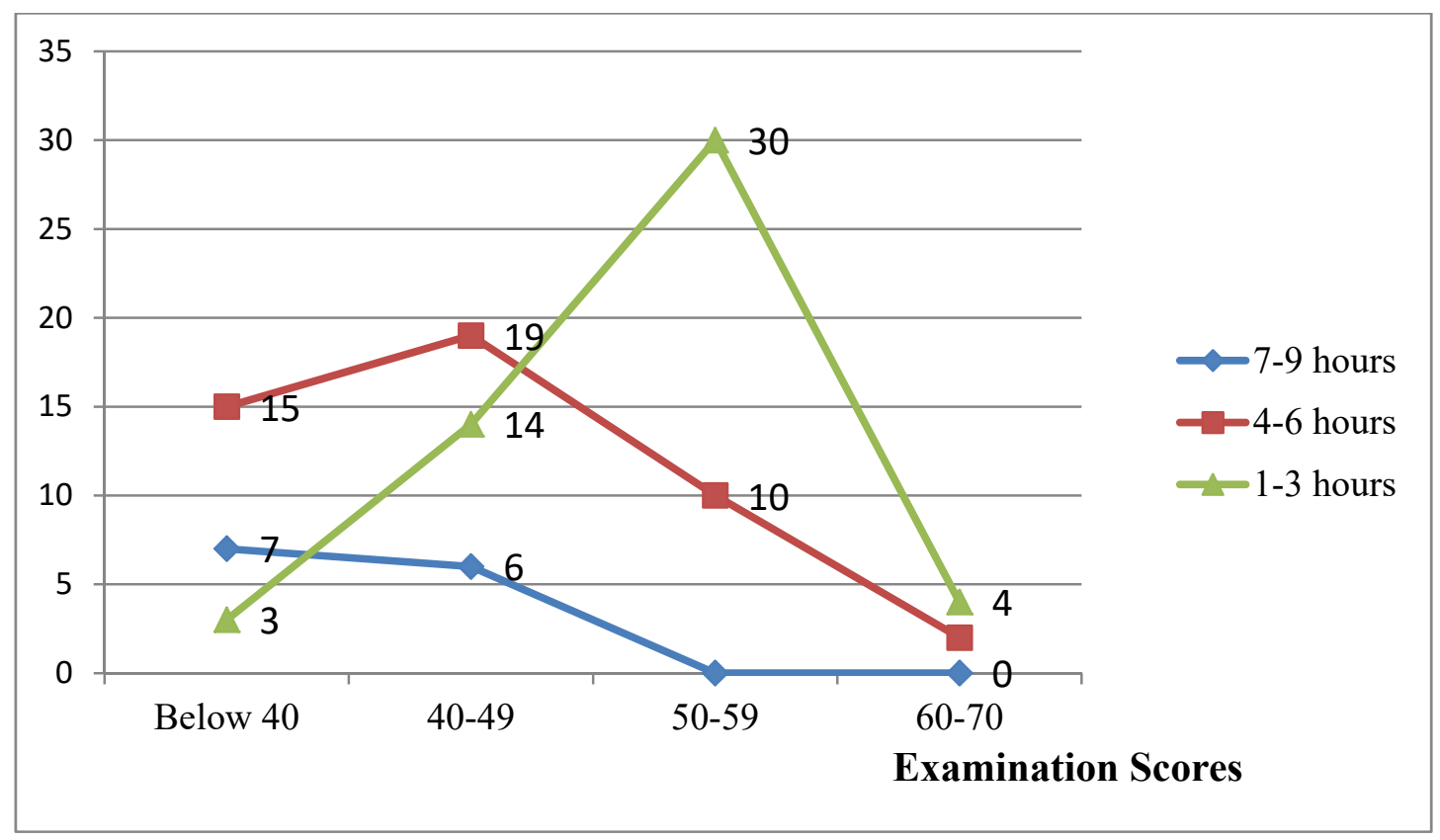

Figure 5. Effect of sleep deprivation on academic performance

Results in Figure 5 revealed that out of the 51 students that have an overall average of 1-3 hours of sleep during schools days, weekends and examination, 3 (5.9\%) respondents scored below 40 marks; 14 (27.1\%) respondents scored between 40-49 marks; $30(58.8 \%)$ respondents scored between 50-59 marks, while 4(7.8\%) respondents scored between 60-70 marks. Also, out of the 45 students that have an average of 4-6 hours of sleep during schools days, 15 (32.6\%) respondents scored below 40 marks; 19 (41.3\%) respondents scored between 40-49 marks; 9 (19.6\%) respondents scored between 50-59 marks, while 2(4.3\%) respondents scored between 60-70 marks. Lastly, out of the 13 students that have an average of 7-9 hours of sleep during schools days, 7 (53.8\%) respondents scored below 40 marks, while 6(46.2\%) respondents scored between 40-49 marks. The results implied that students who had less sleep had better scores than their colleagues who spent most of their time (4-6 hours and 79 hours) sleeping. 
Specific objective four: To examine how sleep deprivation influence male and female nursing students' academic performance of university of Calabar

Table 3. Male and female nursing students' average hours of sleep during school days, weekends and examination

\begin{tabular}{|c|c|c|c|c|c|c|}
\hline \multirow[b]{2}{*}{ Average hours of sleep } & \multicolumn{3}{|c|}{ Male $(\mathrm{N}=27)$} & \multicolumn{3}{|c|}{ Female $(\mathrm{N}=82)$} \\
\hline & $\bar{X}$ & SD & $\begin{array}{l}\text { Mean } \\
\text { Exam sc. }\end{array}$ & $\bar{X}$ & SD & Mean Exam sc \\
\hline During school days & 5.02 & .267 & 45.2 & 5.25 & .572 & 44.0 \\
\hline During weekends & 5.07 & .351 & 37.3 & 5.43 & .53 & 36.5 \\
\hline During examination & 2.39 & .44 & 51.2 & 4.77 & .37 & 50.5 \\
\hline Total & 12.48 & 1.058 & 133.7 & 15.45 & 1.472 & 131 \\
\hline Average & 4.16 & .35 & 44.6 & 5.15 & .49 & 43.7 \\
\hline
\end{tabular}

Results in Table 3 revealed that male students have a sleep mean (SD) score of $4.16 \pm .35$ with an examination mean score of 44.6, while their female counterparts have sleep mean (SD) score of $5.15 \pm .49$ with an examination mean score of 43.7. These results imply that male students deprive themselves of sleep more than female students, and their examination scores were also slightly higher than those of female students.

\section{Test of Hypotheses}

There is no significant relationship between sleep deprivation and academic performance of nursing students of Calabar university of Calabar.

Table 4. Pearson's correlation of relationship between sleep deprivation and academic performance of nursing student's Independent t-test statistics

\begin{tabular}{|c|c|c|c|c|c|c|}
\hline \multirow{2}{*}{ Variable } & & \multirow{2}{*}{$\begin{array}{l}\Sigma X \\
\Sigma Y\end{array}$} & \multirow{2}{*}{$\begin{array}{l}\Sigma \mathbf{X}^{2} \\
\Sigma \mathbf{Y}^{2}\end{array}$} & \multirow{2}{*}{$\Sigma X Y$} & \multirow{2}{*}{ R-value } & \multirow{2}{*}{ p-value } \\
\hline & & & & & & \\
\hline \multirow[t]{2}{*}{ Sleep deprivation } & $(\mathrm{X})$ & 509 & 4705 & & & \\
\hline & & & & 20982 & 0.382 & $<.05$ \\
\hline Academic performance & $(\mathrm{Y})$ & 4812 & 212465 & & & \\
\hline
\end{tabular}

The results of data analysis in Table 4 revealed that at 0.05 level of significance the calculated r-value of 0.382 is higher than the critical value of 0.194 . This is an indication that the result is significant. Therefore, the null hypothesis $\left(\mathrm{H}_{0}\right)$ which states that there is no significant relationship between sleep deprivation and academic performance of nursing students of Calabar university of Calabar was rejected. It implied that sleep deprivation relates to academic performance of nursing students. It suggests that that when students deprive themselves of sleep to read for examinations, their academic performances are enhanced.

Hypothesis two: There is no significant influence of sleep deprivation on academic performance of male and female nursing students of University of Calabar. 
Table 5. Independent t-test statistics of influence of sleep deprivation and academic performance of nursing students

\begin{tabular}{lllllll}
\hline Gender & $\mathbf{N}$ & $\mathbf{X}$ & SD & t- Cal & t-Crit & Decision \\
\hline Male & 27 & 4.16 & 0.35 & $3.07^{*}$ & \multirow{2}{*}{1.969} & Rejected \\
Female & 82 & 5.15 & 0.49 & & & \\
\hline
\end{tabular}

$\mathrm{P}>.05 ; \alpha=.05 ; \mathrm{df}=298 ;$ Critical $\mathrm{t}=1.969 ;$ Calculated $\mathrm{t}=3.07^{*}$.

The result of data analysis in Table 5 revealed that the calculated t-value of $3.07 *$ is higher than the critical t-value of 1.969 at 0.05 level of significance with 298 degrees of freedom (df). The result is statistically significant. Therefore, the null hypothesis was rejected. This result therefore implies that there is a significant influence of sleep deprivation on academic performance of male and female nursing students of Calabar university of Calabar.

\section{Discussion}

The results of this study revealed that most 55(50.5\%) of the respondents start depriving themselves of sleep immediately after resumption (Figure 1) with $36(33.0 \%$ ) of them waking up more than thrice a night to read. During school days, most 51(46.8\%) respondents sleep for 1-3 hours on average, $45(41.3 \%)$ percent respondents sleep for 4-6 hours on average, while 13 (11.9\%) respondents sleep for 7-9 hours. This result complements that of (Raley, et al. 2016) who found out that on the average students had 6.40 hours, 6.74 hours and 6.82 hours of sleep daily. During weekends, most 69(63. \%) respondents sleep for 4-6 hours on average, only $8(7.4 \%)$ percent respondent sleep for 7-9 hours. This could be as a result of religious, cultural and social activities that as reported by Lund, et al. (2010) that during weekends, students go to bed late and wake up late compared to during school days. The result also showed that during examination majority, 73(67.0.3\%) of the respondents sleep for 1-3 hours on average.

In comparing when male and female nursing students start depriving themselves of sleep, the study revealed that 63.0 percent of males start depriving themselves of sleep immediately after resumption as against 46.3 percent of females (Figure 4$)$. Nearly twenty-six percent $(25.9 \%)$ of $2(1.8 \%)$ respondents sleep for $7-9$ hours. Thus, the students sleep less than the recommended sleep time for an adult, which is 7-8 hours in the night, in order to study. These results are lower than that of Otenyo (2015), who found out that on average majority of students sleep 6-8 hours per night. Findings further revealed that most respondents 64(58.7\%) take substances such as coffee, and take tea, energy drinks, soft drinks, and cigarette to keep awake at night. 45(41.33\%) respondents did not take any substance to keep awake at night; This result in in consonance with that of Otenyo (2015) and Cebulko (2010); that students used substances such as teas, alcohol, energy and caffeinated drinks to deprive themselves of sleep. These substances constitute drug abuse and can in the future lead to serious addiction, culminating to abnormal behavior and increase crime rate.

Furthermore, the study revealed that male students have an average sleep of 5.02 hours during schools days; 5.07 hours during weekends, and 2.39 hours during examinations, whereas female students have an average sleep of 5.25 hours during schools days, 5.43 hours during weekends, and 4.77 hours during examinations (Table 2). It was evident that, male students sleep less than female students, thus showing a relationship between gender and sleep hours. This result is contrary to that of Cates et al. (2014), who found no relationship between gender and overall sleep among students.

A significant positive relationship between sleep deprivation and academic performance of nursing students was revealed. Students who deprived themselves of sleep by sleeping for 1-3 hours a night, especially during examination had higher examination scores than those that sleep for 4-6 hours and 7-9 hours respectively; implying that the more a student deprived his or herself from sleep to read, the better the academic performance. This result is contrary to the findings of Sarbazvatan et al. (2017), Hershner and Chervin (2014), Aung and Nurumal 2016 and Orzech et al. (2011) Desouky et al. (2015) which pointed that sleep deprivation affects academic performance of students negatively. The result further contradicts that of Stroebele et al. (2013), which revealed among others that sufficient sleep ( $>9$ hours/night) was associated with high school grades. Similarly, Ghandi (2013) and Dotillos et al. (2015) did not find any association between sleep deprivation and academic performance. Abraham and Scaria (2015) also reported that there is insufficient evidence to make a judgment as to whether the sleep deprivation can have an impact on the academic performance of students.

The result further showed a significant influence of sleep deprivation on academic performance of male and female nursing students of University of Calabar. Male students who have a lower mean (SD) hours of sleep of (4.16 \pm .35$)$ 


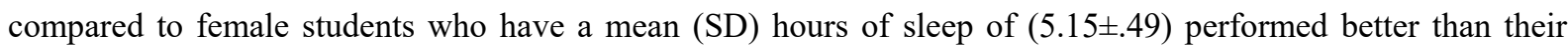
female counterparts. This corresponds with the result of literature review by Abraham and Scaria (2015), which revealed that decreased sleep has a positive impact on students' academic performance, but contrary to Raley, et al (2016), who reported no significant difference in the quality of sleep by gender. The findings of this study seem to differ from the popular opinion that adults should sleep between $7-8$ hours in the night.

\section{Conclusion}

This study explored sleep deprivation and academic performance among undergraduate nursing students. The result revealed a significant relationship between sleep deprivation and academic performance of nursing students, and also a significant influence of sleep deprivation on academic performance of male and female nursing students contrary to popular findings. Although it is recommended that adults should sleep for at least 7 to 8 hour a day or in a night in order to maintain and improve health, it is important for students to deprive themselves of sleep in order to read for examination; given the fact that students attend lectures in the day, they need to read at night if they must succeed.

\section{Recommendations}

Undergraduate nursing students should be educated on the importance of adequate sleep to their academic performance and high score achievement in their study. They should only deprive themselves of sleep by sleeping for at least 4-6 hours during school days but less during examination. Nursing students should create a nightly routine such as relaxation activities that will help them prepare body for a good night's sleep. This should include exercise and avoid doing anything in bed such as watch television other than sleeping and resting. They should avoid practices of taking substances to prevent sleep. If they have to take substances that contain caffeine and nicotine, it should be four to six hours before they go to sleep, and be careful not to become addicted. Lecturers/Teachers should schedule lectures to allow students enough time to rest, do assignments and do personal studies.

\section{Competing Interests Statement}

The authors declare that there are no competing or potential conflicts of interest.

\section{References}

Abraham, J., \& Scaria, J. (2015). Influence of sleep in academic performance - an integrated review of literature. IOSR Journal of Nursing and Health Science (IOSR-JNHS), 4(Issue 4), 78-81. https://doi.org/10.9790/1959-04477881

Al Ghamdi, A. A. (2013). Sleep deprivation and academic performance of students in the Collage of Nursing at King Saud University. World Applied Sciences Journal, 27(2), 155-167. https://doi.org/10.5829/idosi.wasj.2013.27.02.8141

Aung, K. T., \& Nurumal, M. S. (2016). Sleep quality and academic performance of nursing students. Retrieved from https://www.semanticscholar.org/paper/

Cates, M. E., Clark, A., Woolley, T. W., \& Saunders, A. (2014). Sleep quality among pharmacy students. American Journal of Pharmaceutical Education, 79(1), Article 09. https://doi.org/10.5688/ajpe79109

Cebulko, N. (2010). Description of sleep quality and behaviors in Baccalaureate nursing students: Literature review and methods. The Ohio State University Nursing Honors.

Dotillos, D. Z., Orong, A. P., Payangga, A., Proel, M., Simyunn, X. M., \& Torregosa, C. D. (2011). Preferences of study time and academic performance among third year nursing students. Advancing Nursing Research, 3, 1-13. http://dx.doi.org/10.7828/anrj.v3i1.269

El Desouky, E. M., Lawend, J. A., \& Awed, H. (2015). Relationship between quality of sleep and academic performance Among Female Nursing Students. International Journal of Nursing Didactics, 5(9), 6-13. http://dx.doi.org/10.15520/ijnd.2015.vol5.iss9.111.06-13

Eliasson, A. H., \& Lettieri, C. J. (2010). Early to bed, early to rise! Sleep habits and academic performance in college students. Sleep Breath, 14, 71-75. https://doi.org/10.1007/s11325-009-0282-2

Gomes, A. A., Tavares, J., \& de Azevedo, M. P. (2011). Sleep and academic performance in undergraduates: A multi-measure, multi-predictor approach. Chronobiology International, 28(9), 786-801. https://doi.org/10.3109/07420528.2011.606518

Hershner, S. D., \& Chervin, R. D. (2014). Causes and consequences of sleepiness among college students. Nature 
and Science of Sleep, 6, 73-84. https://doi.org/10.2147/NSS.S62907

Lund, H. G., Reider, B. D., Whiting, A. B., \& Prichard, J. R. (2010). Sleep patterns and predictors of disturbed sleep in a large population of college students. The Journal of Adolescent Health: Official Publication of the Society for Adolescent Medicine, 46(2), 124-132. https://dx.doi.org/10.1016/j.jadohealth.2009.06.016

Mak, K. K., Lee, S. L., Ho, S. Y., Lo, W. S., \& Lam, T. H. (2012). Sleep and academic performance in Hong Kong adolescents. $J$ Sch Health., 82(11), 522-7. https://doi.org/10.1111/j.1746-1561.2012.00732.x

Orzech, K. M., Salafsky, D. B., \& Hamilton, L. A. (2011). The state of sleep among college students at a large public university. Journal of American College Health, 59(7), 612-619. https://doi.org/10.1080/07448481.2010.520051

Otenyo, K. O. (2015). Sleeping habits and sleep deprivation among college students (A Bachelor's Degree Thesis submitted to the University of Arizona. University of Arizona Repository). Retrieved from http://hdl.handle.net/10150/579300

Raley, H., Naber, J., Cross, S., \& Perlow, M. (2016). The impact of duration of sleep on academic performance in University students. Madridge J Nurs., 1(1), 11-18. https://doi.org/10.18689/mjn-1000103

Sarbazvatan, H., Amini, A., Aminisani, N., \& Shamshirgaran, S. M. (2017). Sleep quality and academic progression among students of Tabriz University of Medical Sciences, Northwest of Iran. Res Dev. Med Educ, 6(1), 29-33. https://doi.org/10.15171/rdme.2017.006

Shochat, T., Cohen-Zion, M., \& Tzischinsky, O. (2014). Functional consequences of inadequate sleep in adolescents: A systematic review. Sleep Medicine Reviews, 18(1), $75-87$. https://doi.org/10.1016/j.smrv.2013.03.005

Stroebele, N., McNally, J., Plog, A., Siegfried, S., \& Hill, J. O. (2013). The Association of Self-reported Sleep, Weight Status and Academic Performance in Fifth Grade Students' Sch Health. Journal of School Health, 83(2), 77-84. https://doi.org/10.1111/josh.12001

Thomas, C. M., McIntosh, C. E., \& Lamar, R. (2016). Sleep deprivation and the potential impact on nursing students practice and health. Retrieved from http://www.nursinglibrary.org/vhl/handle/10755/620294

van der Helm, E., \& Walker, M. P. (2012). Sleep and Affective Brain Regulation. https://doi.org/10.1111/j.1751-9004.2012.00464.x

Vyazovskiy, V. V. (2015). Sleep, recovery, and metaregulation: explaining the benefits of sleep. Nat Sci Sleep, 7 , 171-184. https://doi.org/10.2147/NSS.S54036

Watson, N. F., Badr, M. S., Belenky, G., Bliwise, D. L., Buxton, O. M., \& Buysse D. (2015). Recommended amount of sleep for a healthy adult: a joint consensus statement of the American Academy of Sleep Medicine and Sleep Research Society. J Clin Sleep Med., 11(6), 581-592. https://doi.org/10.5664/jcsm.4758

Young, S., \& Bramham, J. (2012). Cognitive-Behavioral Therapy for ADHD in Adolescents and Adults: A Psychological Guide to Practice. London: John Wiley \& Sons. https://doi.org/10.1002/9781119943440 


\section{Appendix 1}

Results of General Qualifying Exams For Nursing (Dept. of Nursing Science, UNICAL 2010-2018)

\begin{tabular}{|c|c|c|c|}
\hline Year & Month & Number of candidates & Percentage \\
\hline \multirow[t]{2}{*}{2010} & May & 34 & 68 \\
\hline & November & 38 & 68 \\
\hline \multirow[t]{2}{*}{2011} & May & 15 & 40 \\
\hline & November & 22 & 68 \\
\hline \multirow[t]{2}{*}{2012} & May & 16 & 31 \\
\hline & November & 16 & 69 \\
\hline \multirow[t]{2}{*}{2013} & May & 64 & 48 \\
\hline & November & 61 & 44 \\
\hline \multirow[t]{2}{*}{2014} & May & 81 & 58 \\
\hline & November & 54 & 43 \\
\hline \multirow[t]{2}{*}{2015} & May & 40 & 35 \\
\hline & November & 58 & 43 \\
\hline \multirow[t]{2}{*}{2016} & May & 41 & 39 \\
\hline & November & 38 & 47 \\
\hline \multirow[t]{2}{*}{2017} & May & 60 & 28 \\
\hline & November & 20 & 96 \\
\hline \multirow[t]{2}{*}{2018} & May & 77 & 25.97 \\
\hline & November & 79 & 28 \\
\hline
\end{tabular}

Source: From, Nursing \& Midwifery Council of Nigeria (N\&MCN) book of Registered Nurses (RN), School by school Results for Cross River State.

\section{Copyrights}

Copyright for this article is retained by the author(s), with first publication rights granted to the journal.

This is an open-access article distributed under the terms and conditions of the Creative Commons Attribution license (http://creativecommons.org/licenses/by/4.0/). 